\title{
Mechanisms for DNA-damaging agent-induced inactivation of ErbB2 and ErbB3 via the ERK and p38 signaling pathways
}

\author{
CHUL MIN PARK, YUKI KAWASAKI, ALAA REFAAT and HIROAKI SAKURAI \\ Department of Cancer Cell Biology, Graduate School of Medicine and Pharmaceutical Sciences, \\ University of Toyama, Toyama 930-0194, Japan
}

Received April 19, 2016; Accepted February 23, 2017

DOI: $10.3892 / \mathrm{ol} .2017 .7532$

\begin{abstract}
Cisplatin (CDDP) and doxorubicin (DOX) are chemotherapeutic drugs that trigger apoptosis by inducing DNA-damage. A previous study using breast cancer cells demonstrated the negative feedback modulation of the epidermal growth factor receptor (EGFR) and receptor tyrosine-protein kinase erbB-2 (ErbB2) via extracellular signal-regulated kinase (ERK)-mediated phosphorylation of conserved Thr-669 and Thr-677 residues, respectively, in the juxtamembrane domain. In addition, CDDP has been identified to cause negative feedback inhibition of activated EGFR in lung cancer cells. In the present study, the role of phosphorylation in the feedback control of the ErbB2/ErbB3 heterodimer in human breast and gastric cancer cells was investigated. Phosphorylation of ErbB2 at Thr-677 was induced by CDDP and DOX, which in turn reduced tyrosine autophosphorylation of ErbB2 and ErbB3. Treatment with trametinib, a mitogen-activated protein kinase inhibitor that blocks ERK-mediated Thr-677 phosphorylation, and substitution of Thr-677 to alanine, blocked the feedback inhibition of ErbB2 and ErbB3. In addition, these agents caused the degradation of ErbB proteins through the activation of $\mathrm{p} 38$ mitogen-activated protein kinase (p38) and ERK. These results demonstrate that chemotherapeutic agents trigger ERK- and p38-mediated post-translational downregulation of ErbB receptors.
\end{abstract}

\section{Introduction}

The receptor tyrosine-protein kinase erbB (ErbB) family of receptor tyrosine kinases (RTKs) consists of four members, ErbB1 [also known as epidermal growth factor receptor

Correspondence to: Professor Hiroaki Sakurai, Department of Cancer Cell Biology, Graduate School of Medicine and Pharmaceutical Sciences, University of Toyama, Toyama 930-0194, Japan

E-mail: hsakurai@pha.u-toyama.ac.jp

Key words: receptor tyrosine-protein kinase erbB-2, receptor tyrosine-protein kinase erbB-3, cisplatin, doxorubicin, extracellular signal-regulated kinase, breast cancer
(EGFR)/HER1], ErbB2 (also known as proto-oncogene Neu/HER2), ErbB3 (also termed HER3) and ErbB4 (also termed HER4) (1). Upon activation, ErbB family members form homodimers or heterodimers that serve important roles in biological processes associated with differentiation, proliferation and apoptosis, primarily through mitogen-activated protein kinase and the phosphoinositide-3 kinase/RAC-alpha serine/threonine-protein kinase signaling pathways (2-6). ErbB mutations are frequently identified in human cancer, leading to aberrant ErbB expression and subsequent survival signals (7). Therefore, drugs targeting the ErbB receptors have been a central focus of cancer research $(8,9)$.

RTKs are non-canonically regulated by phosphorylation at their serine and threonine residues. For example, extracellular signal-regulated kinase (ERK)-mediated phosphorylation of a conserved threonine in the juxtamembrane domain of EGFR (Thr-669) and ErbB2 (Thr-677) is a typical negative feedback mechanism of ErbB dimers $(10,11)$. Tumor necrosis factor- $\alpha$-induced and p38 mitogen-activated protein kinase (p38)-mediated phosphorylation of EGFR (Ser-1046/1047) at the C-terminal tail is associated endocytosis of the receptor. A previous study demonstrated that cisplatin (CDDP), a well known DNA-damaging agent, induces the non-canonical phosphorylation of EGFR proteins harboring an activating mutation in lung cancer cells, resulting in negative feedback inhibition and endocytosis (12).

ErbB2, which has been demonstrated to be expressed in $20-30 \%$ of breast cancer cases (13), is usually co-expressed with ErbB3, and together they form a heterodimer that transmits survival signals (14). A typical strategy for treating ErbB2-overexpressing breast cancer is to block its signaling using targeted therapies, including trastuzumab and lapatinib (15); however, resistance to these agents is emerging in clinical settings $(15,16)$. Chemotherapeutic DNA-damaging agents, including doxorubicin (DOX), are frequently used to treat breast tumors (17); therefore, in the current study the effects of CDDP and DOX on the non-canonical regulation of ErbB2/ErbB3 activation were investigated in breast cancer cells.

\section{Materials and methods}

Antibodies and reagents. The following antibodies were used; phosphorylation (phospho)-specific antibodies 
against ERK (Thr-202 and Tyr-204, cat. no. 9101, 1:2,000 dilution), p38 (Thr-180 and Tyr-182, cat. no. 9211, 1:2,000 dilution), ErbB2 (Tyr-1196, cat. no. 6942, 1:2,000 dilution) and ErbB3 (Tyr-1289, cat. no. 4791, 1:2,000 dilution) (Cell Signaling Technology, Inc., Danvers, MA, USA). In addition, antibodies against ErbB2 (cat. no. sc-284, 1:2,000 dilution), ErbB3 (cat. no. sc-285, 1:2,000 dilution) and actin (cat. no. sc-1615, 1:2,000 dilution) were obtained from Santa Cruz Biotechnology, Inc., Dallas, TX, USA. A monoclonal recombinant antibody against phospho-ErbB2 Thr-677 (clone no. 18-4, 1:1,000 dilution) was generated using the rabbit immunospot array assay on a chip, as described previously $(11,18,19)$. Trametinib (AdooQ BioScience LLC, Irvine, CA, USA) and SB203580 (Merck KGaA, Darmstadt, Germany), CDDP, DOX and G418 (Wako Pure Chemical Industries, Ltd., Osaka, Japan) were also used. All chemical agents were dissolved in dimethylsulphoxide (DMSO), and the final concentration of DMSO was $<0.1 \%$.

Cell culture and treatment. Human BT474, MDA-MB-453 and 293 cells were maintained in Dulbecco's modified Eagle's medium (Thermo Fisher Scientific, Inc., Waltham, MA, USA) supplemented with $10 \%$ fetal calf serum (FCS), $2 \mathrm{mM}$ glutamine, $100 \mathrm{U} / \mathrm{ml}$ penicillin and $100 \mu \mathrm{g} / \mathrm{ml}$ streptomycin. Human MKN45 gastric cancer cells were maintained in RPMI-1640 medium (Gibco; Thermo Fisher Scientific, Inc.) supplemented with $10 \%$ FCS, 2 mM glutamine, $100 \mathrm{U} / \mathrm{ml}$ penicillin and $100 \mu \mathrm{g} / \mathrm{ml}$ streptomycin. Cells were incubated at $37^{\circ} \mathrm{C}$ with $5 \% \mathrm{CO}_{2} .293$ cells were cultured to maintain the transfection stably expressing ErbB2/ErbB3 maintained in media containing $0.5 \mathrm{mg} / \mathrm{ml} \mathrm{G} 418$ (11). Cells were treated with CDDP $(100 \mu \mathrm{M})$ for $3-12 \mathrm{~h}$ or DOX $(10 \mu \mathrm{M})$ for $12-24 \mathrm{~h}$ with or without pretreatment with Trametinib $(0.03 \mu \mathrm{M})$ or SB203580 $(10 \mu \mathrm{M})$ for $30 \mathrm{~min}$.

Transfection. 293 cells were transfected with plasmid DNA (11), encoding human ErbB2 and ErbB3 complementary DNA sequences using Lipofectamine ${ }^{\circledR} 2000$ according to manufacturer's protocol (Invitrogen; Thermo Fisher Scientific, Inc.). The KOD FX neo kit (Toyobo, Co., Ltd., Osaka, Japan) was used for substitution of Thr-677 to Ala (T677A) in ErbB2, as previously described (11).

Western blotting. BT474, MDA-MB-453, 293, and MKN45 whole cell lysates, prepared as described previously $(20,21)$, were resolved using SDS-PAGE (8 or $10 \%$ gel; $15-20 \mu \mathrm{g}$ protein loaded per lane) and transferred to an Immobilon-P nylon membrane (EMD Millipore, Billerica, MA, USA). The membrane was treated with $100 \%$ BlockAce (Dainippon Sumitomo Pharma Co., Ltd., Osaka, Japan) and probed with primary antibodies aforementioned for 2-3 h at room temperature. Antibodies were detected using horseradish peroxidase-conjugated anti-rabbit (cat. no. P0448; 1:2,000) and anti-goat immunoglobulin G (cat. no. P0449, 1:2,000) (Dako; Agilent Technologies, Inc., Santa Clara, CA, USA) and incubated for $1 \mathrm{~h}$ at room temperature. Proteins were visualized using the Pierce ${ }^{\mathrm{TM}}$ enhanced chemiluminescence western blotting substrate (Thermo Fisher Scientific, Inc.). Actin was used as a loading control.

\section{Results}

CDDP induces feedback inhibition of ErbB2 and ErbB3 phosphorylation at Thr-677. A previous study demonstrated that 12-otetradecanoylphorbol-13-acetate (TPA) induces ERK-mediated Thr-677 phosphorylation of ErbB2 (11). Given the role of CDDP in the ERK-mediated phosphorylation of EGFR at Thr-669 in lung cancer cells (22), in the present study the role of CDDP-induced activation of ERK on ErbB2 and ErbB3 phosphorylation in breast cancer cells was investigated. CDDP caused a time-dependent induction of ERK activation and subsequent Thr-677 phosphorylation in BT474 cells (Fig. 1A). Concomitantly, tyrosine phosphorylation of ErbB2 and ErbB3 was markedly reduced (Fig. 1A). Similarly, DOX stimulated ERK activation and Thr-677 phosphorylation, which in turn led to suppression of ErbB2 and ErbB3 tyrosine phosphorylation (Fig. 1B). Similar phosphorylation patterns were observed for ErbB2 and ErbB3 in 293 stably transfected cells (Fig. 1C) and in MDA-MB-453, another ErbB2/ErbB3-overexpressing breast cancer cell line (Fig. 1D). Since CDDP is commonly used for treating gastric cancers (23), the effect of CDDP on ErbB2/3 phosphorylation in the ErbB2-expressing MKN45 gastric cancer cells was examined. As predicted, CDDP induced feedback control of ErbB2 and ErbB3 tyrosine phosphorylation (Fig. 1E). Notably, total ErbB2 and ErbB3 expression was downregulated by either CDDP or DOX treatments in all cell lines (Fig. 1).

Feedback inhibition of ErbB2 and ErbB3 phosphorylation via ERK activation. ERK-mediated threonine phosphorylation of EGFR and ErbB2 is a negative feedback mechanism that regulates their tyrosine autophosphorylation $(10,11,24)$. To confirm the role of ERK activation in ErbB2 phosphorylation at Thr-677, trametinib, a mitogen-activated protein kinase (MAPK)/ERK (MEK) inhibitor approved for use in the treatment of melanoma, was used. Trametinib suppressed ERK activation in ErbB2/ErbB3-expressing BT474 cells and in ErbB2/ErbB3-transfected 293 cells initially induced by CDDP or DOX (Fig. 2). The inhibition of ERK activation was associated with downregulation of Thr-677, and the subsequent restoration of tyrosine phosphorylation of ErbB2 and ErbB3 (Fig. 2).

Role of ErbB2 Thr-677 in feedback inhibition of ErbB2 and ErbB3. A previous study demonstrated the role of TPA-induced ERK phosphorylation of ErbB2 at Thr-677 on the feedback regulation of ErbB2/ErbB3 heterodimer (11). In light of these findings, the feedback inhibition of the ErbB2/ErbB3 heterodimer by Thr-677 phosphorylation in CDDP-treated 293 cells was then investigated. Cells were transiently transfected with either wild-type or T677A-mutated ErbB2 and wild-type ErbB3, and then treated with CDDP for $9 \mathrm{~h}$. Notably, mutated ErbB2-T677A/ErbB3 did not notably respond to CDDP treatment in terms of threonine/tyrosine modulation, yet ERK was activated (Fig. 3).

Potential role for MAPKs in the CDDP-induced degradation of ErbB2 and ErbB3. Western blotting results demonstrated that ErbB2 and ErbB3 are degraded following CDDP or DOX treatments, as demonstrated by the decreased phosphorylation 


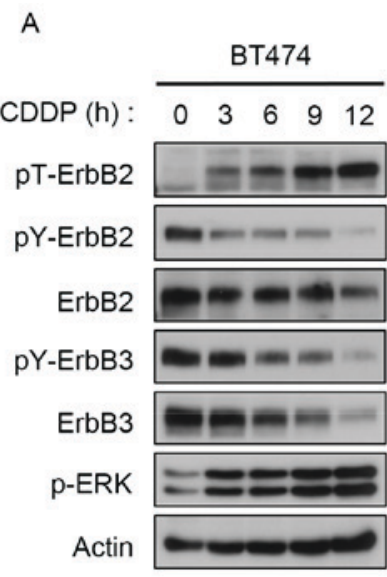

B

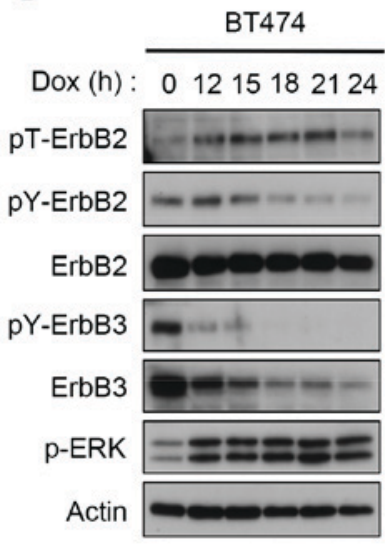

C

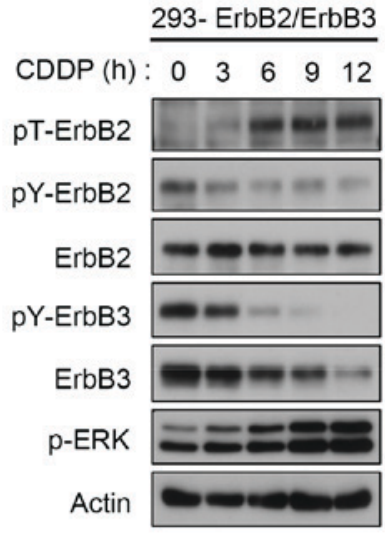

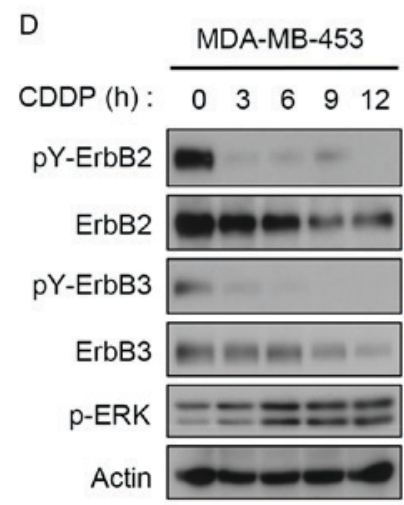

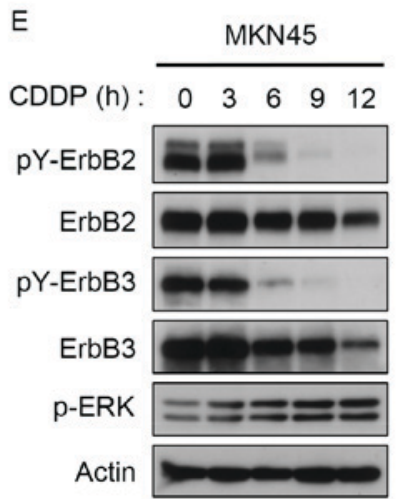

Figure 1. DNA-damaging agents induce feedback inhibition of ErbB2 and ErbB3. Western blotting analysis of (A) BT474 cells treated with $100 \mu \mathrm{M}$ CDDP, (B) BT474 cells treated with $10 \mathrm{mM}$ DOX, (C) 293 cells stably expressing ErbB2 and ErbB3 treated with $100 \mu$ M CDDP, (D) MDA-MB-453 cells treated with $100 \mu \mathrm{M}$ CDDP and (E) MKN45 cells treated with $100 \mu \mathrm{M}$ CDDP for the indicated time points. ErbB, receptor tyrosine-protein kinase erbB; CDDP, cisplatin; DOX, doxorubicin; ERK, extracellular signal-regulated kinase; p, phosphorylated; Y, tyrosine; T, threonine.
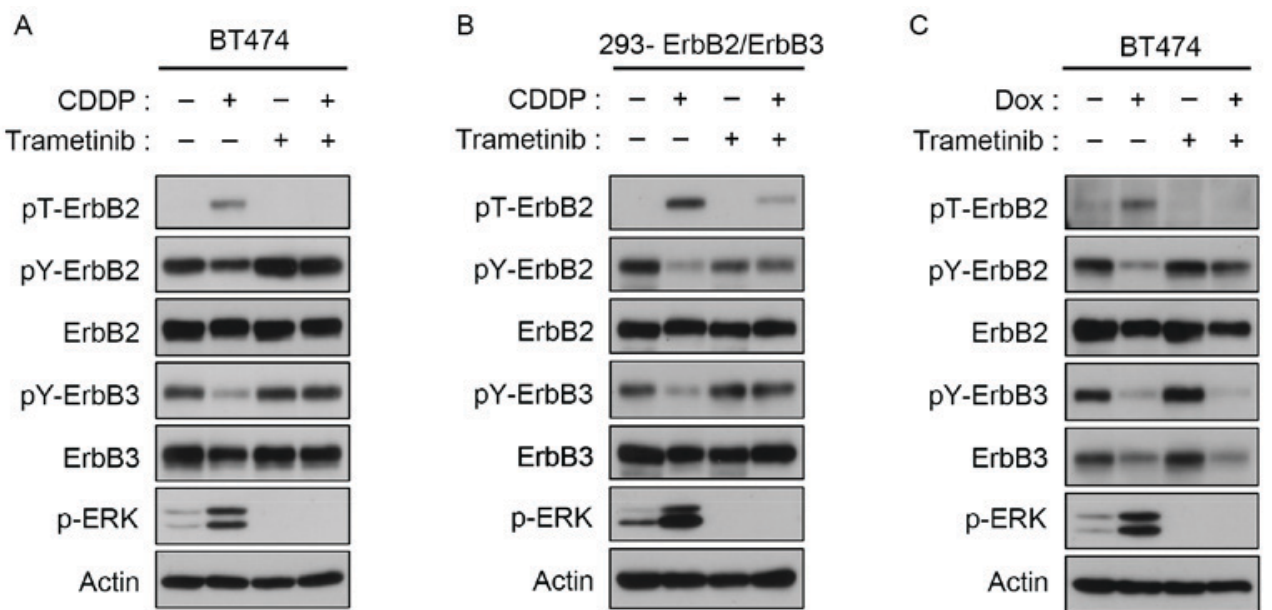

Figure 2. ERK-mediated feedback control of tyrosine phosphorylation of ErbB2/ErbB3. BT474 cells were pretreated with trametinib $(0.03 \mu \mathrm{M})$, and then treated with $100 \mu \mathrm{M}$ CDDP for (A) 9 or (B) $6 \mathrm{~h}$. (C) BT474 cells were pretreated with trametinib $(0.03 \mu \mathrm{M})$, and then treated with DOX (10 $\mu \mathrm{M})$ for $24 \mathrm{~h}$. ErbB, receptor tyrosine-protein kinase erbB; CDDP, cisplatin; DOX, doxorubicin; ERK, extracellular signal-regulated kinase; p, phosphorylated; Y, tyrosine; $\mathrm{T}$, threonine.

observed (Fig. 1A and B). Previous studies have demonstrated that CDDP can cause EGFR degradation, and suggested that this occurs through p38 activation $(25,26)$. In the current study, CDDP induced Thr-677 phosphorylation of ErbB2 through the activation of ERK, and subsequently inhibited tyrosine phosphorylation of ErbB2 and ErbB3. However, the cause of ErbB2 and ErbB3 degradation remains unclear, particularly in the later phase of CDDP treatment. The effects of MAPK inhibitors on CDDP-treated cells were also examined. Degradation of ErbB2 and ErbB3 following 9 h CDDP 


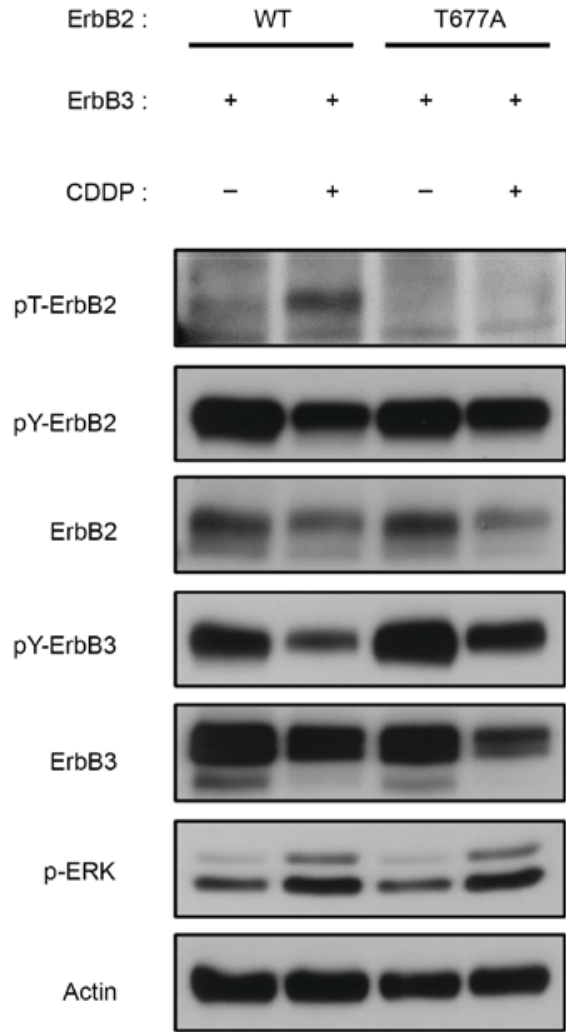

Figure 3. Role of ErbB2 in CDDP-induced feedback inhibition of ErbB2/ErbB3. 293 cells were transiently transfected with expression plasmids for WT and T677A ErbB2. A total of $24 \mathrm{~h}$ following transfection, cells were treated with CDDP for $9 \mathrm{~h}$. ErbB, receptor tyrosine-protein kinase erbB; CDDP, cisplatin; ERK, extracellular signal-regulated kinase; p, phosphorylated; WT, wild-type; Y, tyrosine; T, threonine; T677A, Thr-677 to Ala.

treatment was recovered upon the inhibition of $\mathrm{p} 38$ with SB203580 (Fig. 4). Notably, trametinib, which is primarily used to inhibit ERK phosphorylation, exerted a similar effect on recovering CDDP-induced degradation of ErbB2/3 (Fig. 4). These results suggest that MAPK-mediated protein degradation contributes to the CDDP-induced inactivation of ErbB2 and ErbB3 in ErbB2-overexpressing breast cancer cells.

\section{Discussion}

Phosphoproteomic analyses have identified numerous non-canonical phosphorylation sites in the intracellular domains of RTKs (27); however, their pathophysiological roles in cancer cells remain unclear. Recent studies have investigated the biological significance of the serine/threonine phosphorylation of RTKs in human cancer cells $(10,11,22,24)$. In addition, a previous study demonstrated that chemotherapeutic agents are important regulators of the non-canonical phosphorylation of EGFR through MAPK signaling pathways (22). Therefore, in the current study the regulation of ErbB2 and ErbB3 was investigated.

Similar to previous findings on the feedback inhibition of EGFR in lung cancer cells (22), the current study revealed that the ERK-mediated phosphorylation of a conserved threonine residue of ErbB2 in the juxtamembrane domain is a common feedback inactivation mechanism of ErbB2/ErbB3 heterodimers in breast cancer cells targeted with DNA-damaging

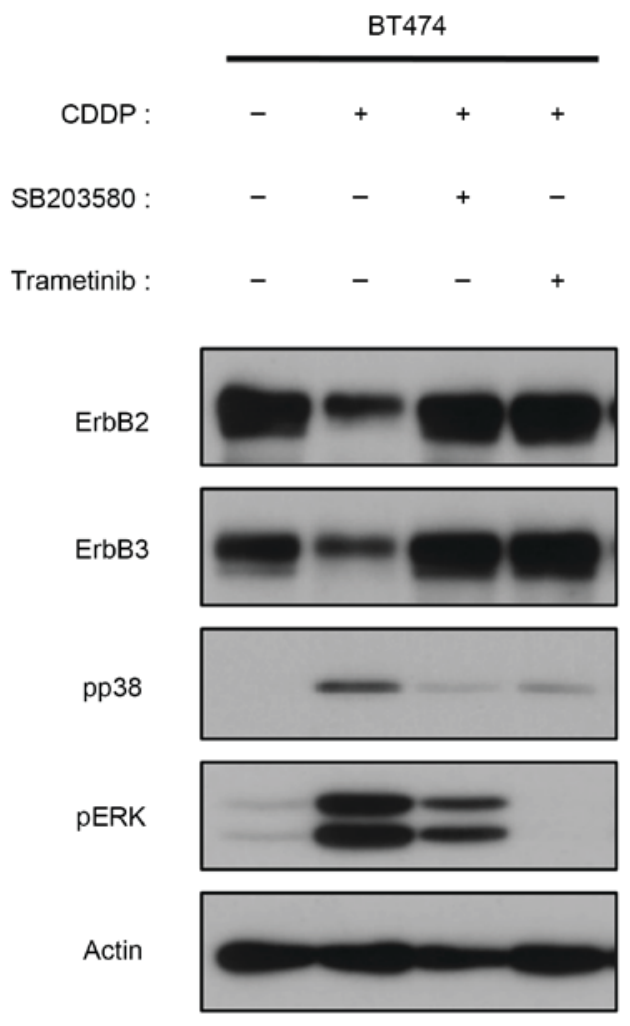

Figure 4. CDDP-induced degradation of ErbB2 and ErbB3 through p38 activation. BT474 cells were pretreated with $0.03 \mu \mathrm{M}$, trametinib or $10 \mu \mathrm{M} \mathrm{SB} 203580$, then treated with $100 \mu \mathrm{M}$ CDDP for $9 \mathrm{~h}$. ErbB, receptor tyrosine-protein kinase erbB; CDDP, cisplatin; ERK, extracellular signal-regulated kinase; p, phosphorylated; p38 mitogen-activated protein kinase.

agents. These agents induce the suppression of protein levels of ErbB2 and ErbB3 through the ERK and p38 MAPK signaling pathways, suggesting a novel non-canonical mechanism of ErbB downregulation. Ahsan et al (28) previously reported that EGFR degradation serves a role in cisplatin-induced cytotoxicity in head and neck cancer. Preliminary results using a Phos-tag have demonstrated that CDDP induces phosphorylation of ErbB members at multiple non-canonical residues (Park, unpublished); therefore, the identification of novel serine/threonine sites that regulate the degradation of ErbB receptors is essential for understanding the underlying molecular mechanisms of chemotherapy-induced inactivation of these receptors.

Notably, relatively high concentrations of CDDP and DOX were used in the present study; however, this is similar to previous studies, of which several also used longer treatment durations $(22,25,29-34)$. Data from a previous study (11), in addition to titration data from the present study, provided the optimum conditions for the phosphorylation of ERK in addition to ErbB2/3. However, further research is required in clinical models to verify these results.

In conclusion, data from the present study demonstrated that DNA-damaging agents cause the inactivation of ErbB2 and ErbB3 via MAPK-mediated ErbB2 phosphorylation and degradation. Trametinib suppressed the CDDP-induced negative feedback regulation of ErbB2/3, suggesting that MEK inhibitors affect the effectiveness of chemotherapy in 
combination with DNA-damaging agents in clinical settings. These observations of the association between tyrosine kinase-dependent canonical activation and serine/threonine phosphorylation-mediated non-canonical regulation of RTKs may aid in the establishment of more effective strategies for cancer treatment, including ways to overcome resistance to anticancer drugs.

\section{Acknowledgements}

The present study was supported by Grants-in-Aid for Scientific Research (grant no. 16H04694), the Ministry of Education, Culture, Sports, Science and Technology (grant no. 16K08366), and a grant from the Tamura Science and Technology Foundation and the Smoking Research Foundation (grant no. 1904).

\section{References}

1. Roskoski R Jr: The ErbB/HER family of protein-tyrosine kinases and cancer. Pharmacol Res 79: 34-74, 2014.

2. Sebastiana S, Settlemanb J, Reshkinc SJ, Azzaritia A, Bellizzia A and Paradisoa A: The complexity of targeting EGFR signalling in cancer: From expression to turnover. Biochim Biophys Acta 1766: 120-139, 2006.

3. Schneider MR and Wolf E: The epidermal growth factor receptor ligands at a glance. J Cell Physiol 218: 460-466, 2009.

4. Singh $A B$ and Harris RC: Autocrine, paracrine and juxtacrine signaling by EGFR ligands. Cell Signal 17: 1183-1193, 2005.

5. Sorkin A and Goh LK: Endocytosis and intracellular trafficking of ErbBs. Exp Cell Res 314: 3093-3106, 2008.

6. Avraham R and Yarden Y: Feedback regulation of EGFR signalling: Decision making by early and delayed loops. Nat Rev Mol Cell Biol 12: 104-117, 2011

7. Pines G, Köstler WJ and Yarden Y: Oncogenic mutant forms of EGFR: Lessons in signal transduction and targets for cancer therapy. FEBS Lett 584: 2699-2706, 2010.

8. Park JW, Neve RM, Szollosi J and Benz CC: Unraveling the biologic and clinical complexities of HER2. Clin Breast Cancer 8: 392-401, 2008.

9. Ménard S, Tagliabue E, Campiglio M and Pupa SM: Role of HER2 gene overexpression in breast carcinoma. J Cell Physiol 182: 150-162, 2000.

10. Sato K, Shin MS, Sakimura A, Zhou Y, Tanaka T, Kawanishi M, Kawasaki Y, Yokoyama S, Koizumi K, Saiki I and Sakurai H: Inverse correlation between Thr-669 and constitutive tyrosine phosphorylation in the asymmetric epidermal growth factor receptor dimer conformation. Cancer Sci 104: 1315-1322, 2013.

11. Kawasaki Y, Sakimura A, Park CM, Tomaru R, Tanaka T, Ozawa T, Zhou Y, Narita K, Kishi H, Muraguchi A and Sakurai H: Feedback control of ErbB2 via ERK-mediated phosphorylation of a conserved threonine in the juxtamembrane domain. Sci Rep 6: 31502, 2016.

12. Dasari $\mathrm{S}$ and Tchounwou PB: Cisplatin in cancer therapy: Molecular mechanisms of action. Eur J Pharmacol 740: 364-378, 2014.

13. Slamon DJ, Clark GM, Wong SG, Levin WJ, Ullrich A and McGuire WL: Human breast cancer: Correlation of relapse and survival with amplification of the HER-2/neu oncogene. Science 235: 177-182, 1987

14. Holbro T, Beerli RR, Maurer F, Koziczak M, Barbas CF III and Hynes NE: The ErbB2/ErbB3 heterodimer functions as an oncogenic unit: ErbB2 requires ErbB3 to drive breast tumor cell proliferation. Proc Natl Acad Sci USA 100: 8933-8938, 2003.

15. Valabrega G, Montemurro F and Aglietta M: Trastuzumab: Mechanism of action, resistance and future perspectives in HER2-overexpressing breast cancer. Ann Oncol 18: 977-984, 2007.

16. Bailey TA, Luan H, Clubb RJ, Naramura M, Band V, Raja SM and Band $\mathrm{H}$ : Mechanisms of Trastuzumab resistance in ErbB2-driven breast cancer and newer opportunities to overcome therapy resistance. J Carcinog 10: 28, 2011.
17. Bezlera M, Hengstlerb JG and Ullricha A: Inhibition of doxorubicin-induced HER3-PI3K-AKT signalling enhances apoptosis of ovarian cancer cells. Mol Oncol 6: 516-529, 2012.

18. Jin A, Ozawa T, Tajiri K, Obata T, Kondo S, Kinoshita K, Kadowaki S, Takahashi K, Sugiyama T, Kishi $H$ and Muraguchi A: A rapid and efficient single-cell manipulation method for screening antigen-specific antibody-secreting cells from human peripheral blood. Nat Med 15: 1088-1092, 2009.

19. Ozawa T, Piao X, Kobayashi E, Zhou Y, Sakurai H, Andoh T, Jin A, Kishi $\mathrm{H}$ and Muraguchi A: A novel rabbit immunospot array assay on a chip allows for the rapid generation of rabbit monoclonal antibodies with high affinity. PLoS One 7: e52383, 2012.

20. Sakurai H, Miyoshi H, Toriumi W and Sugita T: Functional interactions of transforming growth factor beta-activated kinase 1 with IkappaB kinases to stimulate NF-kappaB activation. J Biol Chem 274: 10641-10648, 1999.

21. Sakurai H, Suzuki S, Kawasaki N, Nakano H, Okazaki T, Chino A, Doi T and Saiki I: Tumor necrosis factor-alpha-induced IKK phosphorylation of NF-kappaB p65 on serine 536 is mediated through the TRAF2, TRAF5, and TAK1 signaling pathway. J Biol Chem 278: 36916-36923, 2003.

22. Refaat A, Aminullah, Zhou Y, Kawanishi M, Tomaru R, Abdelhamed S, Shin MS, Koizumi K, Yokoyama S, Saiki I and Sakurai H: Role of tyrosine kinase-independent phosphorylation of EGFR with activating mutation in cisplatin-treated lung cancer cells. Biochem Biophys Res Commun 458: 856-861, 2015.

23. Cunningham D, Allum WH, Stenning SP, Thompson JN, Van de Velde CJ, Nicolson M, Scarffe JH, Lofts FJ, Falk SJ, Iveson TJ, et al: Perioperative chemotherapy versus surgery alone for resectable gastroesophageal cancer. N Engl J Med 355: 11-20, 2006.

24. Nishimura M, Shin MS, Singhirunnusorn P, Suzuki S, Kawanishi M,Koizumi K, Saiki I and Sakurai H: TAK1-mediated serine/threonine phosphorylation of epidermal growth factor receptor via p38/extracellular signal-regulated kinase: NF- $\{$ kappa\}B-independent survival pathways in tumor necrosis factor alpha signaling. Mol Cell Biol 29: 5529-5539, 2009.

25. Kim KK, Han A, Yano N, Ribeiro JR, Lokich E, Singh RK and Moore RG: Tetrathiomolybdate mediates cisplatin-induced p38 signaling and EGFR degradation and enhances response to cisplatin therapy in gynecologic cancers. Sci Rep 5: 15911, 2015.

26. Frey MR, Dise RS, Edelblum KL and Polk DB: p38 kinase regulates epidermal growth factor receptor downregulation and cellular migration. EMBO J 25: 5683-5692, 2006.

27. Hornbeck PV, Kornhauser JM, Tkachev S, Zhang B, Skrzypek E, Murray B, Latham V and Sullivan M: PhosphoSitePlus: A comprehensive resource for investigating the structure and function of experimentally determined post-translational modifications in man and mouse. Nucleic Acids Res 40 (Database Issue): D261-D270, 2012.

28. Ahsan A, Hiniker SM, Ramanand SG, Nyati S, Hegde A, Helman A, Menawat R, Bhojani MS, Lawrence TS and Nyati MK: Role of epidermal growth factor receptor degradation in cisplatin-induced cytotoxicity in head and neck cancer. Cancer Res 70: 2862-2869, 2010.

29. Benhar M, Engelberg D and Levitzki A: Cisplatin-induced activation of the EGF receptor. Oncogene 21: 8723-8731, 2002.

30. Winograd-Katz SE and Levitzki A: Cisplatin induces PKB/Akt activation and p38(MAPK) phosphorylation of the EGF receptor. Oncogene 25: 7381-7390, 2006.

31. Boone JJ, Bhosle J, Tilby MJ, Hartley JA and Hochhauser D: Involvement of the HER2 pathway in repair of DNA damage produced by chemotherapeutic agents. Mol Cancer Ther 8: 3015-3023, 2009.

32. Campiglio M, Somenzi G, Olgiati C, Beretta G, Balsari A, Zaffaroni N, Valagussa $\mathrm{P}$ and Ménard S: Role of proliferation in HER2 status predicted response to doxorubicin. Int J Cancer 105: 568-573, 2003.

33. Li X, Lu Y, Liang K, Liu B and Fan Z: Differential responses to doxorubicin-induced phosphorylation and activation of Akt in human breast cancer cells. Breast Cancer Res 7: R589-R597, 2005.

34. De U, Chun P, Choi WS, Lee BM, Kim ND, Moon HR, Jung JH and Kim HS: A novel anthracene derivative, MHY412, induces apoptosis in doxorubicin-resistant MCF-7/Adr human breast cancer cells through cell cycle arrest and downregulation of P-glycoprotein expression. Int J Oncol 44: 167-176, 2014. 